\title{
Development and Validation of HPTLC Method for Estimation of Safinamide Mesylate in Bulk and in Tablet Dosage Form
}

\author{
Vivekkumar K. Redasani, Bhushan J. Mali, and Sanjay J. Surana \\ Department of Pharmaceutical Chemistry, R. C. Patel Institute of Pharmaceutical Education \& Research, \\ Dhule District, Shirpur 425 405, India \\ Correspondence should be addressed to Vivekkumar K. Redasani, minvi224@rediffmail.com
}

Received 1 January 2012; Accepted 14 February 2012

Academic Editors: G. Drochioiu, G. Erny, A. Jimenez, and G. Vecchio

Copyright ( 2012 Vivekkumar K. Redasani et al. This is an open access article distributed under the Creative Commons Attribution License, which permits unrestricted use, distribution, and reproduction in any medium, provided the original work is properly cited.

\begin{abstract}
A simple, specific, and precise high-performance thin-layer chromatographic method has been developed and validated for estimation of Safinamide Mesylate as bulk and in tablet dosage form. The chromatographic development was carried out on aluminum plates precoated with silica gel 60 F254 using a mixture of Toluene: Methanol: Triethylamine (4:1:0.5 v/v) as mobile phase. Detection was carried out densitometrically at $226 \mathrm{~nm}$. The $R_{F}$ value of drug was found to be $0.54 \pm 0.02$. The method was validated with respect to linearity, accuracy, precision, and robustness. The calibration curve was found to be linear over a range of $400-2400 \mathrm{ng} \mu \mathrm{L}^{-1}$. The $\%$ assay (Mean \pm S.D.) was found to be $100.27 \pm 0.72$. Accuracy of the method was accessed by percentage recovery and found to be $99.77 \pm 0.71 \%$. Thus the proposed HPTLC method was found to provide fast and cost-effective quantitative control for routine analysis of Safinamide mesylate as bulk and in tablet dosage form.
\end{abstract}

\section{Introduction}

Safinamide (SAF) is an orally available derivative from chemical class of $\alpha$-amino amides, with multiple mechanisms of action involving inhibition of mono-amino oxidase $B$ and dopamine reuptake used in the treatment of epilepsy and parkinson's disease. Chemically, Safinamide is $(S)-(+)-2-$ [4-(3-fluorobenzyloxybenzylamino) propanamide] methane sulfonate (1:1 salt) (Figure 1) [1,2].

Literature survey reveals a validated chiral liquid chromatographic method for the enantiomeric separation of safinamide mesylate [3] and bioassay of safinamide in biological fluids of humans and various animal species [4].

Except this, so far no analytical method was available for estimation of SAF as indicated by detail literature survey. The therapeutic effectiveness and less methods available for its estimation encourage us to undertake this work, so that quantitative estimation of SAF can be done and hence can be used for routine analysis of bulk and formulation as well.

The present study describes the development and validation of a simple, specific, sensitive, accurate precise, and economic HPTLC method for determination of SAF in tablet dosage form. The proposed method is optimized and validated as per the International Conference on Harmonization (ICH) guidelines $[5,6]$.

\section{Experimental}

2.1. Chemicals and Reagents. Safinamide mesylate was kindly gifted from Alkem Pharmaceuticals, Mumbai (Maharashtra), India. Safinamide tablets were obtained from commercial sources within their shelf life period. All the reagents and solvents used were of analytical reagent (AR) grade. Solvents used like toluene, methanol, and triethylamine were of AR grade and obtained from Merck Chemicals.

2.2. Instrumentation and Chromatographic Conditions. The samples were spotted in the form of bands of width of $6 \mathrm{~mm}$ with a Camag $100 \mu \mathrm{L}$ sample syringe (Hamilton, Bonaduz, Switzerland) on precoated silica gel aluminum plate 60 F254 ( $20 \mathrm{~cm} \times 10 \mathrm{~cm}$ with $0.2 \mathrm{~mm}$ thickness) supplied by Anchrom technologists (Mumbai) using a CAMAG Linomat 5 sample applicator (Switzerland). A constant application rate of $200 \mathrm{~nL} \mathrm{sec}^{-1}$ was employed, and the space between two bands 
<smiles>COC(N)=O</smiles>

FIgURE 1: Chemical structure of Safinamide Mesylate.



Figure 2: Chromatogram of standard safinamide mesylate $\left(R_{F}\right.$ 0.54 ) measured at $226 \mathrm{~nm}$.

was $15.4 \mathrm{~mm}$. The slit dimension was kept $6 \mathrm{~mm} \times 0.45 \mathrm{~mm}$. The mobile phase consisted of toluene: methanol:triethylamine $(4: 1: 0.5 \mathrm{v} / \mathrm{v})$ was selected, which gave sharp and symmetrical peak with $R_{F} 0.54$. The optimized chamber saturation time was $15 \mathrm{~min}$ at room temperature $\left(25^{\circ} \mathrm{C} \pm 2{ }^{\circ} \mathrm{C}\right)$ and relative humidity $60 \% \pm 5 \%$. The length of chromatogram run was approximately $8 \mathrm{~cm}$. Subsequent to the development, TLC plates were dried with the help of an air dryer. Densitometric scanning was performed using Camag TLC scanner 3 equipped with win CATS software version 1.3.0 at $226 \mathrm{~nm}$. The source of radiation utilized was deuterium lamp emitting a continuous UV spectrum in the range of 200-400 nm. Evaluation was performed using peak area with linear regression.

2.3. Preparation of Standard Stock Solution. An accurately weighed quantity of $10 \mathrm{mg}$ SAF was transferred to $10 \mathrm{~mL}$ volumetric flasks, dissolved in methanol, and volume was made up to mark with the same solvent to obtain a working standard having concentration $1000 \mathrm{ng} \mu \mathrm{L}^{-1}$.
TABLe 1: Analysis of Tablet formulation (Label claim: $50 \mathrm{mg}$ per tablet).

\begin{tabular}{lccc}
\hline $\begin{array}{l}\text { Concentration } \\
\left(\mathrm{ng} \mu \mathrm{L}^{-1}\right)\end{array}$ & $\begin{array}{c}\text { Amount found } \\
(\mathrm{ng})\end{array}$ & $\begin{array}{c}\text { Amount found } \\
(\%)\end{array}$ & \% R.S.D. \\
\hline & 1008.8 & 100.8 & \\
& 999.76 & 99.97 & \\
1000 & 995.63 & 99.56 & \\
& 1006.7 & 100.6 & \\
& 1011.3 & 101.1 & \\
& 994.14 & 99.41 & \\
\hline Mean \pm S.D. & $1002.7 \pm 7.22$ & $100.2 \pm 0.72$ & 0.72 \\
\hline
\end{tabular}

2.4. Optimization of HPTLC Method. Initially, different ratios of methanol, chloroform, n-propanol, and toluene were tried, but tailing of spots was observed. Finally, the mobile phase toluene:methanol:triethylamine (4:1:0.5\% $\mathrm{v} / \mathrm{v}$ ) gives good resolution, sharp and symmetrical peak with $R_{F}$ value of 0.54 at $226 \mathrm{~nm}$ (Figure 2).

2.5. Application of Proposed Method to Tablet Formulation. To determine the concentration of SAF in tablets (Label claim: $50 \mathrm{mg}$ per tablet), the contents of 20 tablets were weighed, their mean weight determined, and were finely powdered. The powder equivalent to $10 \mathrm{mg}$ of SAF was weighed. The drug from the powder was extracted with methanol. To ensure complete extraction of the drug, it was sonicated for $20 \mathrm{~min}$ and the volume was made up to $10 \mathrm{~mL}$. The resulting solution was filtered using $0.41 \mu \mathrm{m}$ filter (Millifilter, Milford, MA). The above solution was applied on TLC plate (1000 ng per spot) followed by development and scanning as described in above chromatographic conditions (Table 1).

\section{Method Validation}

The proposed method was validated as per the ICH guidelines in terms of its linearity, accuracy, specificity, intraday and interday precision, robustness, ruggedness, limit of detection (LOD), and limit of quantification (LOQ).

3.1. Linearity (Calibration Curve). For linearity study, aliquots of $0.4,0.8,1.2,1.6,2.0$, and $2.4 \mu \mathrm{L}$ of SAF from standard stock solution was applied on TLC plate to obtain the concentration of 400,800,1200,1600, 2000, and $2400 \mathrm{ng} /$ band. TLC plates were developed under the above-established conditions. Area under peak was recorded and plotted against concentration (Figure 3 ).

3.2. Accuracy. The preanalyzed samples of concentration $1000 \mathrm{ng} \mu \mathrm{L}^{-1}$ were over spotted with excess 80, 100, and $120 \%$ of standard drug. The total concentrations of the drug was determined $(n=3)$, to check for the recovery of the drug at different levels in formulation.

3.3. Specificity. The specificity of the method was ascertained by analyzing standard drug and formulation. The spot for SAF in formulation was confirmed by comparing the $R_{F}$ values and spectra of the spot with that of standard. The peak 


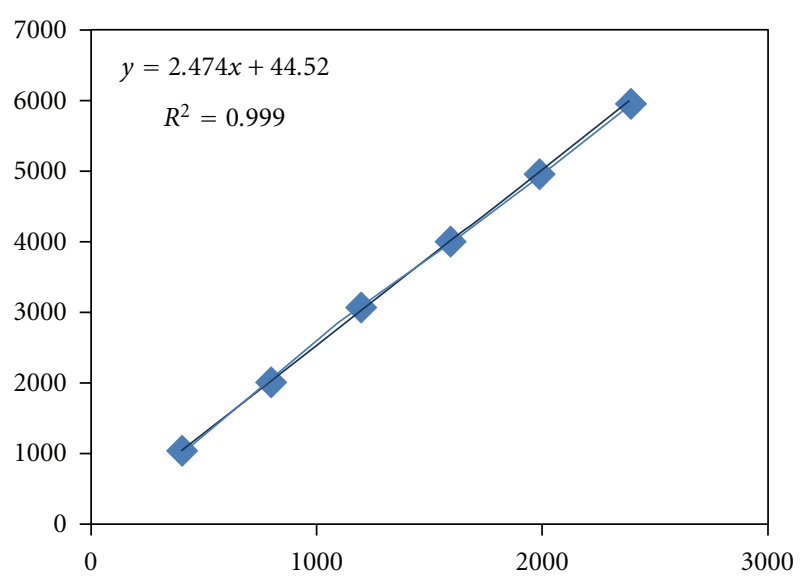

FIgURe 3: Calibration curve for Safinamide mesylate in concentration 400-2400 ng/band.

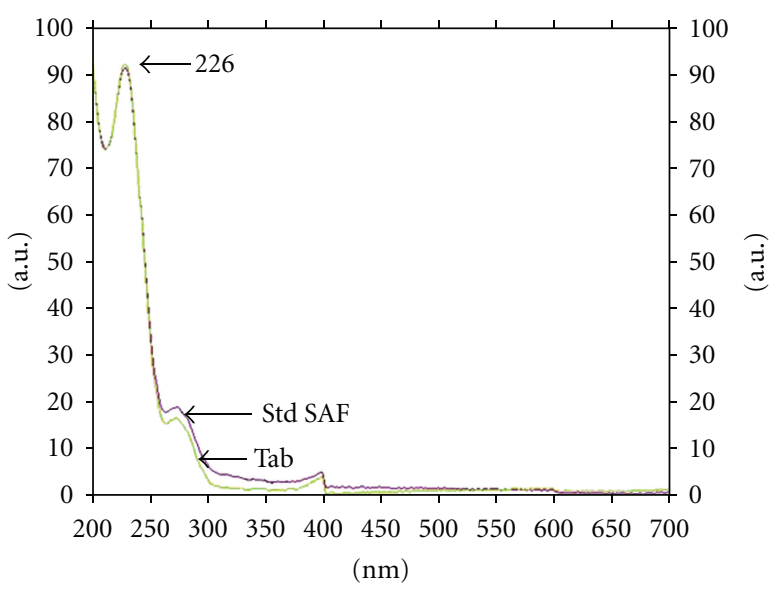

FIgURE 4: A typical overlain spectrum of standard drug and drug extracted from tablet scanned at the peak-start, peak-apex, and peak-end positions of the band (Correlation > 0.99).

purity of SAF was assessed by comparing the spectra at three different levels, that is, peak start $(S)$, peak apex $(M)$, and peak end $(E)$ positions of the spot. A typical overlain spectrum of standard drug and drug extracted from tablet is shown in Figure 4.

3.4. Precision. Repeatability was determined by spotting $1200 \mathrm{ng}$ per spot of SAF. Precision of the method was assessed by spotting 800,1200 , and $1600 \mathrm{ng}$ per spot of SAF on three different times within the same day (intraday) and on three different days (interday).

3.5. Robustness. Robustness of the method was performed by spotting $1200 \mathrm{ng}$ of drug making small deliberate changes in various chromatographic conditions. Mobile phases having different composition of toluene:methanol:TEA $(3.8: 1.2: 0.5$ and $4.3: 0.7: 0.2 \mathrm{v} / \mathrm{v})$ were tried, and chromatograms were run. The volume of mobile phase, temperature, and relative humidity was varied in the range of $\pm 5 \%$.
TABLE 2: Results of recovery studies.

\begin{tabular}{lccc}
\hline $\begin{array}{l}\text { Initial amount of } \\
\text { drug }\left(\mathrm{ng} \mu \mathrm{L}^{-1}\right)\end{array}$ & $\begin{array}{c}\text { \% of standard } \\
\text { drug added }\end{array}$ & \% Recovery* & \% R.S.D. \\
\hline 1000 & 80 & 99.44 & 0.31 \\
1000 & 100 & 99.88 & 0.33 \\
1000 & 120 & 99.86 & 0.41 \\
\hline
\end{tabular}

${ }^{*}$ Mean of three estimations at each level.

The plates were prewashed by methanol and activated at $60 \pm$ $5^{\circ} \mathrm{C}$ for 2,5 , and $7 \mathrm{~min}$ prior to chromatography. Time from spotting to chromatography and from chromatography to scanning was varied as 0,20 , and $40 \mathrm{~min}$.

3.6. Ruggedness. Ruggedness of the method was performed by spotting $1200 \mathrm{ng}$ of drug by two different analysts maintaining same experimental and environmental conditions.

3.7. Limit of Detection (LOD) and Limit of Quantification (LOQ). In order to determine detection and quantification limit, concentrations in the lower part of the linear range of the calibration curve were used. SAF solutions of 400,480 , $560,640,720$, and $800 \mathrm{ng} \mu \mathrm{L}^{-1}$ were prepared and applied in triplicate. The LOQ and LOD were calculated using equation $\mathrm{LOD}=3.3 \times N / B$ and LOQ $=10 \times N / B$, where $N$ is standard deviation of the peak areas of the drugs $(n=3)$, taken as a measure of noise, and $B$ is the slope of the corresponding calibration curve.

\section{Results and Discussion}

4.1. HPTLC Method Development. The TLC procedure was optimized with a view to develop a method for determination of SAF. Optimization of mobile phase with toluene: methanol : triethylamine $(4: 1: 0.5) \mathrm{v} / \mathrm{v}$ gives sharp and symmetrical peak having $R_{F}$ value of $0.54 \pm 0.2$. It was observed that prewashing of TLC plates with methanol (followed by drying and activation) and presaturation of TLC chamber with mobile phase for $15 \mathrm{~min}$ ensures good reproducibility and peak shape.

\subsection{Validation}

4.2.1. Linearity. The linear regression data for the calibration curves showed good linear relationship over the concentration range $400-1200 \mathrm{ng} \mu \mathrm{L}^{-1}$. Linear regression equation was found to be $Y=2.474 X+44.52\left(r^{2}=0.999\right)$.

4.2.2. Accuracy. The proposed method when used for extraction and subsequent estimation of drug from tablet dosage form after over spotting with 80,100 , and $120 \%$ of additional drug; mean recovery is within acceptable limits, indicating the method is accurate and afforded recovery of 99.44$99.88 \%$ (Table 2).

4.2.3. Specificity. The peak purity of SAF was assessed by comparing the spectra at three different levels, that is, peak start $(S)$, peak apex $(M)$, and peak end $(E)$ positions of 
Table 3: Intraday and Interday Precision.

\begin{tabular}{lcccc}
\hline Conc. $\left(\mathrm{ng} \mu \mathrm{L}^{-1}\right)$ & \multicolumn{2}{c}{ Intraday } & \multicolumn{2}{c}{ Interday } \\
\hline 800 & \% Amount found* & \% R.S.D. & \% Amount found* & 0.16 \\
1200 & 99.99 & 0.30 & 99.76 & 0.13 \\
1600 & 100.04 & 0.24 & 99.97 & 0.09 \\
\hline
\end{tabular}

${ }^{*}$ Mean of three estimations at each level.

TABLE 4: Robustness of the method.

\begin{tabular}{lc}
\hline Parameters & \% R.S.D.* \\
\hline Mobile phase composition & 0.90 \\
Mobile phase volume & 0.81 \\
Development distance & 0.65 \\
Activation of TLC plate & 0.81 \\
Duration of saturation & 0.70 \\
Time from spotting to chromatography & 0.50 \\
Time from chromatography to scanning & 0.43 \\
\hline
\end{tabular}

* Mean of three estimations at each level.

TABLE 5: Results of ruggedness study.

\begin{tabular}{lcc}
\hline Analyst & \% Amount found of SAF (Mean \pm S.D.) & \% R.S.D.* \\
\hline I & $99.97 \pm 0.67$ & 0.67 \\
II & $100.07 \pm 0.66$ & 0.66 \\
\hline
\end{tabular}

${ }^{*}$ Mean of three estimations at each level.

the spot and the results obtained as $r^{2}(S, M)=0.999$ and $r^{2}(M, E)=0.998$. Good correlation was obtained between standard and sample spectra of SAF.

4.2.4. Precision. The precision of the developed HPTLC method was expressed in terms of $\%$ RSD. The results depicted revealed high precision of the method (Table 3 ).

4.2.5. Robustness. The standard deviation of peak areas was calculated for each parameter, and \% RSD was found to be less than $2 \%$ (Table 4 ).

4.2.6. Ruggedness. The \% RSD was found to be less than $2 \%$ indicating the method was rugged when estimation was done by two different analysts, Table 5 .

4.2.7. $L O D$ and $L O Q$. Detection limit and quantification limit for SAF were found to be $13.09 \mathrm{ng}$ and $39.67 \mathrm{ng}$, respectively. This indicates adequate sensitivity of the method as it can be validated in less quantity of drug, and hence the method proves to be economic.

\section{Conclusion}

The literature survey promoted us to develop HPTLC method on SAF as no analytical method was reported for it. The HPTLC method was developed and validated as per ICH guidelines, and the method was found to simple, precise, accurate reproducible, and economic, thus can be used for determination of SAF in tablets. Moreover, proposed method also indicates no interference of excipients when applied to tablet dosage form. Future plan includes development of Safinamide mesylate in available combinations along with stability-indicating and forced degradation-studies.

\section{Acknowledgments}

The authors are thankful to Alkem Pharmaceuticals Ltd. (Mumbai, Maharashtra) for providing a gift sample of Safinamide Mesylate.

\section{References}

[1] M. Onofrj, L. Bonanni, and A. Thomas, "An expert opinion on safinamide in Parkinson's disease," Expert Opinion on Investigational Drugs, vol. 17, no. 7, pp. 1115-1125, 2008.

[2] A. Marzo, L. Dal Bo, N. C. Monti et al., "Pharmacokinetics and pharmacodynamics of safinamide, a neuroprotectant with antiparkinsonian and anticonvulsant activity," Pharmacological Research, vol. 50, no. 1, pp. 77-85, 2004.

[3] K. Zhang, N. Xue, X. Shi, W. Liu, J. Meng, and Y. Du, "A validated chiral liquid chromatographic method for the enantiomeric separation of safinamide mesilate, a new anti-Parkinson drug," Journal of Pharmaceutical and Biomedical Analysis, vol. 55, no. 1, pp. 220-224, 2011.

[4] L. Dal Bo, P. Mazzucchelli, M. Fibbioli, and A. Marzo, "Bioassay of safinamide in biological fluids of humans and various animal species," Drug Research, vol. 56, no. 12, pp. 814-819, 2006.

[5] ICH-Guidelines Q2A, "Validation of Analytical Procedures: Definition and terminology," (CPMP III/5626/94), Geneva, Switzerland, 1995.

[6] ICH-Guidelines Q2B, "Validation of Analytical Procedures: Methodology," (CPMP/ICH/281/95) Geneva, Switzerland 1996. 


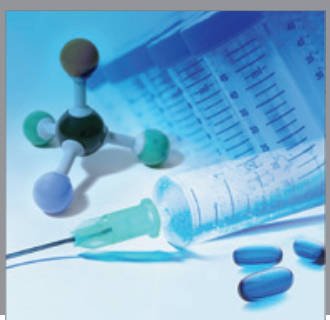

International Journal of

Medicinal Chemistry

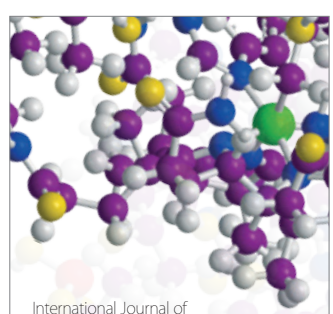

Carbohydrate Chemistry

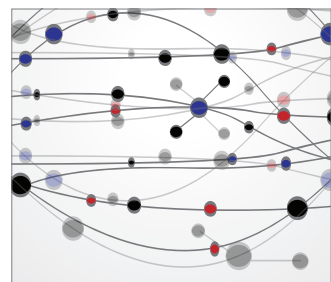

The Scientific World Journal
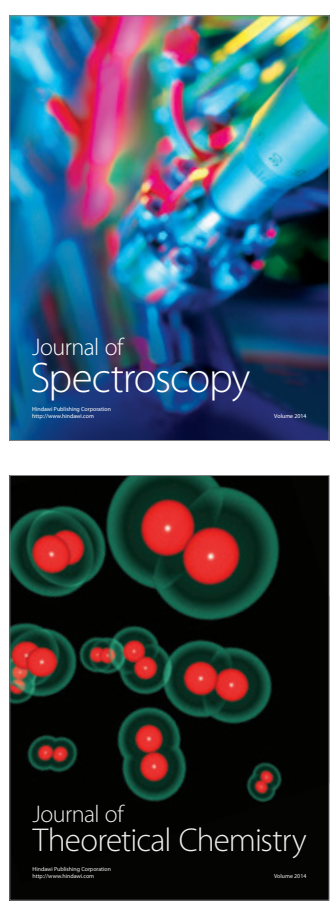
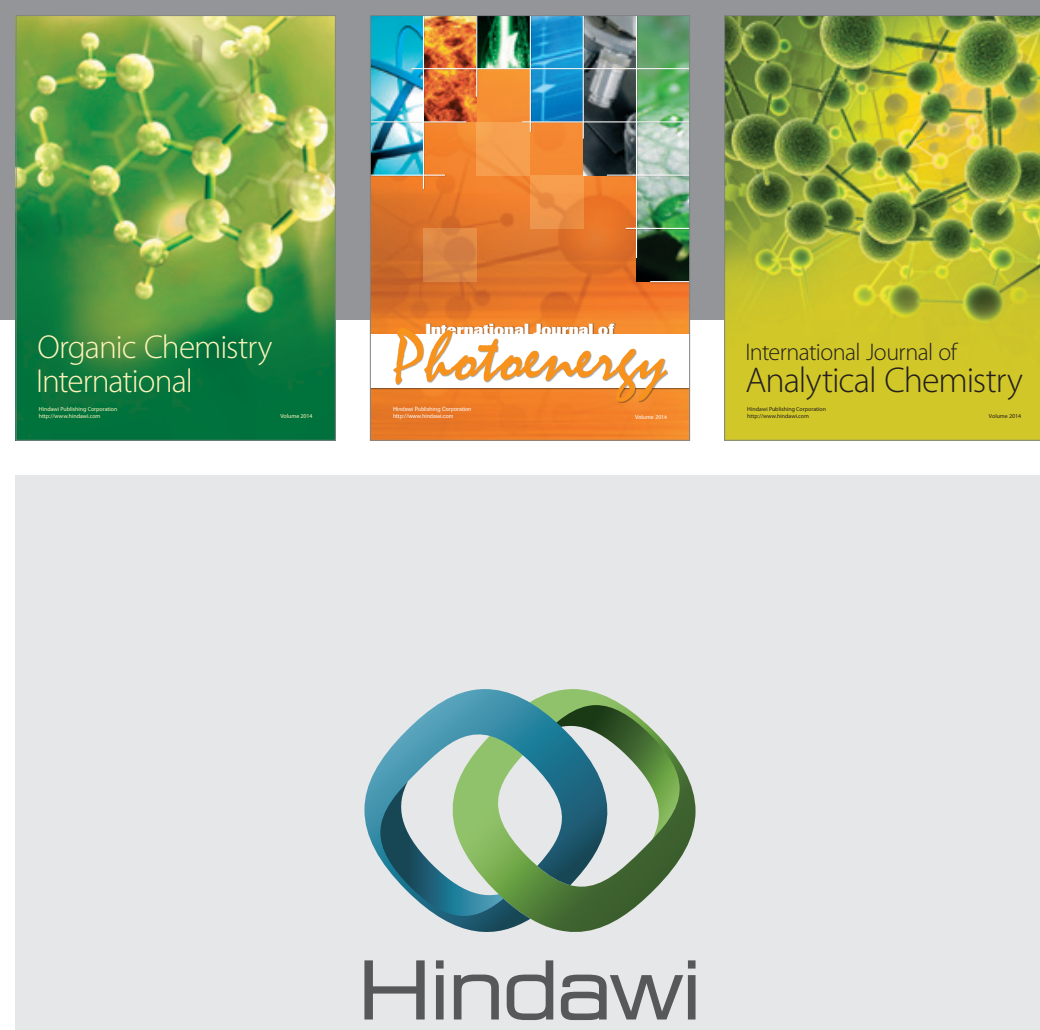

Submit your manuscripts at

http://www.hindawi.com


Journal of

Applied Chemistry

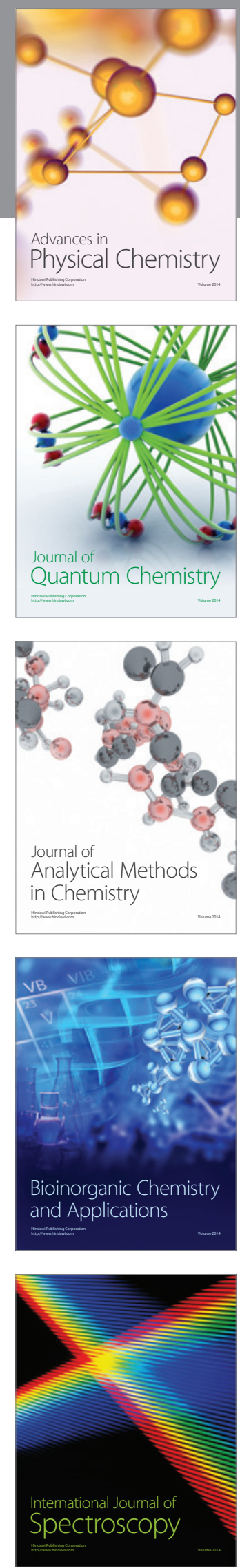